\title{
THE WAKEFIELDS AND LOSS FACTORS IN SUPERCONDUCTING ACCELERATING CAVITIES FOR TESLA COLLIDER
}

\author{
E. Plawski \\ The Andrzej Soltan Institute for Nuclear Studies, Swierk, P-10 \\ 05-400 Otwock-Swierk, Poland
}

\begin{abstract}
The first stage of TTF superconducting electron linac is a in its final state of assembling. Many of superconducting accelerating cavities attained already the planned for collider accelerating fields of $25 \mathrm{MV} / \mathrm{m}$. However the problem of cost reduction of TESLA accelerating system is still actual. The propositions concerning modifications in accelerating cavities were signalled at several TESLA Meetings and reported also at the PAC97 Conference [1]. The cavities are the main source of wakefields, leading to beam instabilities in a linear collider. In the frame of scientific international cooperation the part of the work concerning the wakefield generation in new structures proposed by DESY was done in our Institute. The room temperature copper models of new type cavities were also produced in Swierk and will undergo the tests at DESY.

In this report the calculated longitudinal and transverse loss factors in enlarged iris cavity proposed in [1] and in superstructure composed of four 7-cell cavities [2] are compared with the corresponding values [3] in cavities currently used in TTF.
\end{abstract}

\section{INTRODUCTION}

The experience already gained during the development of $1.3 \mathrm{GHz}$ superconducting RF accelerating cavities for TESLA collider indicates that some design parameters should be reconsidered having in mind the cost reduction of the future collider. This problem was reported on PAC'97 Conference [1] and on several TESLA Meetings [2] where the new shapes of accelerating cavity and cavities' arrangements were proposed. The points considered were the shape of the cavity and fill factor (the ratio of active acceleration length to total length) of the collider. The present design of TTF superconducting accelerating cavity consists of 9 weakly coupled cellsresonators operated in $\pi$ mode at frequency $1.3 \mathrm{GHz}$. The string of 8 cavities each equipped with FM power coupler and 2 HOM couplers is encapsulated in a single unitmodule and cooled down to $2 \mathrm{~K}$. The shapes of RF accelerating cavity elaborated some years ago $[4,5]$ were optimized to have possibly high coupling impedance (R/Q) for fundamental mode, to keep the safe values of the peak surface electric and magnetic fields and to keep small values of HOM impedances. The small iris aperture which is a compromise between the above criteria reduces the coupling factor $\mathrm{k}_{\mathrm{cc}}$ between cells of the cavity. As the error of field amplitude in a standing wave cavity made of $\mathrm{N}$ cells is proportional to $\mathrm{N}^{2} / \mathrm{k}_{\mathrm{cc}}$, the small value of $\mathrm{k}_{\mathrm{cc}}$ makes the actual cavities very sensitive to technological processing during cavity preparation. This has impact on cavity production costs. To avoid the fundamental mode RF phase interference between neighbouring cavities the $3 \lambda 2$ lengths beam tubes were chosen. This reduces the effective accelerating field by the ratio of cavity active length to total cavity length.

Two ways to solve this problem were proposed in last two years. In [1] it is proposed to enlarge the iris aperture and to enlarge also the end tube diameters of the cavity in order to facilitate the HOM damping.

The second approach [2] preserves the shape of TTF cavity inner cells but limits to 7 the number of cells in one cavity. The diameter of interconnecting beam tubes is increased and their length limited to $\lambda / 2$ allowing the transmission of RF power from cavity to cavity. The set of 4 cavities (superstructure) is fed by $1 \mathrm{RF}$ input power coupler.

The accelerating cavities are the main source of wakefields and related losses in a linac. The proposed changes influence significantly the wakes induced in cavities. The wake-potentials and loss factors were calculated for both proposed schemes and are reported in this paper.

\section{WAKE-POTENTIALS}

The wakes induced in a cavity by the gaussian bunch of standard deviation $\sigma=1 \mathrm{~mm}$ or $0.5 \mathrm{~mm}$ were evaluated by the procedure ABCI [6] used earlier for the actual TTF cavity wakefield calculations. For the case of large iris cavity this enables the direct comparison with TTF RF cavity regardless of possible systematic inaccuracy due to finite size of mesh dimensions used or possible imperfections inherent to the computation code used .

\subsection{The large iris cavity}

The changes of shapes proposed in [1] for a new cavity are illustrated in Fig. 1 and listed in Table 1.Each cell of the new cavity has elliptical shape in the equator region and circular with the $17 \mathrm{~mm}$ curvature radius at the iris aperture. End cells have slightly smaller equator radius to compensate the influence of the beam tube opening. The detailed data on optimized shapes of inner and outer cells were taken from [1]. 
Table1.

\begin{tabular}{|c|c|c|}
\hline & TTF 9-cell cavity & Large iris 9- \\
\hline $\mathrm{R}_{\text {iris }}$ of inner & $35 \mathrm{~mm}$ & $51 \mathrm{~mm}$ \\
\hline $\mathrm{R}_{\text {equator }}$ of inner & $103.3 \mathrm{~mm}$ & $108.08 \mathrm{~mm}$ \\
\hline $\mathrm{R}_{\text {equator }}$ of outer & $103.30 \mathrm{~mm}$ & $106.6 \mathrm{~mm}$ \\
\hline $\mathrm{R}_{\text {tube }}$ of end & $39 \mathrm{~mm}$ & $55 \mathrm{~mm}$ \\
\hline
\end{tabular}

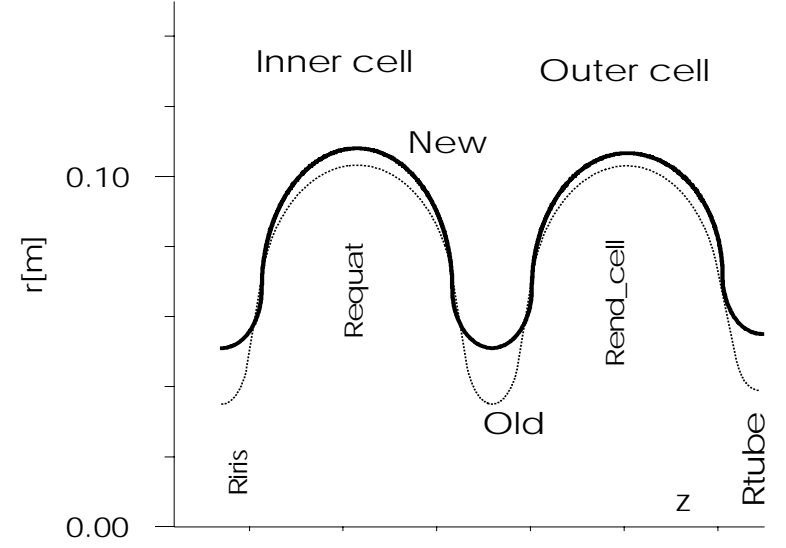

Fig. 1 Proposed modification of shape of 9-cell cavity.

The longitudinal (monopole) wakes induced in 9-cell cavity by $\sigma=1 \mathrm{~mm}$ bunch are illustrated in Fig.2. The comparison is made between two cavities. Curve 1 shows the wake induced in the new cavity and curve 2 the wake in the old one at present in use in TTF.

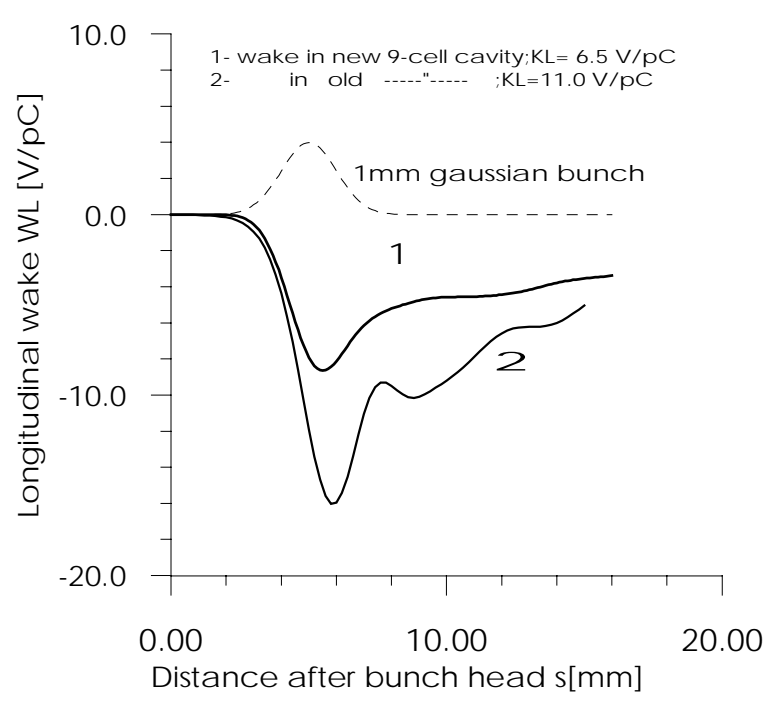

Fig. $2 \mathrm{~W}_{\|}$wake induced in 9-cell cavities.

The resulting loss factors for both cavities are summarised in Table 2. The listed monopole loss factors $\mathrm{k}_{\|}$include also the loss to fundamental mode passband.

For the $\sigma=1 \mathrm{~mm}$ bunch, the plot of longitudinal loss factor integrated up to $100 \mathrm{GHz}$ is shown in Fig.3. The clean steps on this plot correspond to the increase of loss factor due to successive resonant modes. The fundamental mode loss factor read from this plot is equal

Table 2. The loss factors of 9-cell TESLA cavities

\begin{tabular}{|c|c|c|c|c|}
\hline $\begin{array}{c}\sigma_{\text {bunch }} \\
{[\mathrm{mm}]}\end{array}$ & \multicolumn{2}{|c|}{$\begin{array}{c}\text { TTF cavity } \\
\mathrm{k}_{\|}[\mathrm{V} / \mathrm{pC}]\end{array} \mathrm{k}_{\perp}[\mathrm{V} / \mathrm{pC} / \mathrm{m}]$} & \multicolumn{2}{c|}{$\begin{array}{c}\text { New } 9 \text { cell cavity } \\
{[\mathrm{V} / \mathrm{pC}]}\end{array}$} \\
\hline 1.0 & 11.05 & 20.6 & 6.53 & 6.21 \\
\hline 0.5 & 15.58 & 12.96 & 10.20 & 4.74 \\
\hline
\end{tabular}

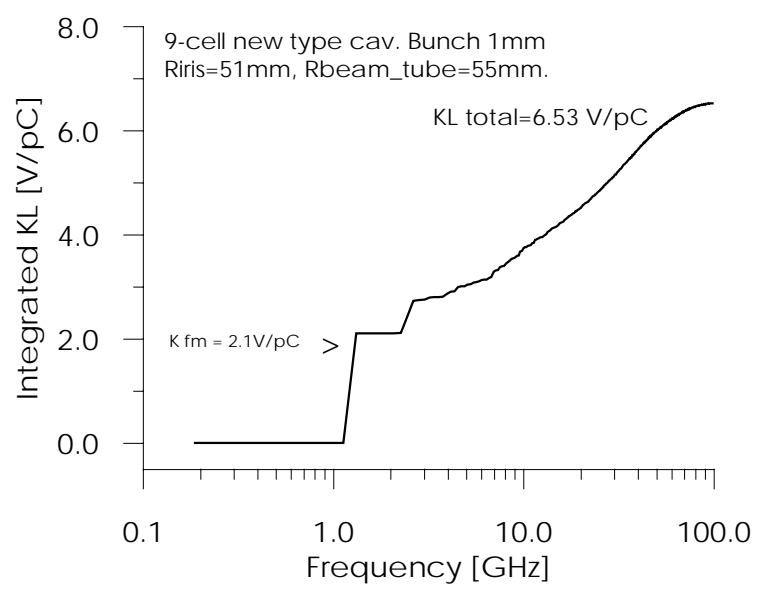

Fig. 3 Integrated longitudinal loss factor in the new type 9-cell accelerating cavity. $\sigma=1 \mathrm{~mm}$, gaussian

to $2.11 \mathrm{~V} / \mathrm{pC}$. The HOM loss factor of monopole modes is then: $\quad \mathrm{k}_{\| \text {ном }}=\mathrm{k}_{\| \text {total }}-\mathrm{k}_{\| \text {fm }}=4.4 \mathrm{~V} / \mathrm{pC}$

for a new type 9-cell cavity.

\subsubsection{Consequences}

The opening of iris and beam tube apertures of 9-cell TESLA cavity as proposed in [1] has clear advantage as far as the loss factors are concerned. The $\mathrm{k}_{\|}$is reduced by the factor of 1.7 and $k_{\perp}$ by the factor of 3.3 when the new and old cavities are compared taking a bunch of $\sigma=1 \mathrm{~mm}$ The value of longitudinal loss factor of HOM is $4.4 \mathrm{~V} / \mathrm{pC}$ in the new cavity; that parameter calculated in [3] for old cavity is $8.97 \mathrm{~V} / \mathrm{pC}$. The transverse loss factor is reduced from $20.6 \mathrm{~V} / \mathrm{pC} / \mathrm{m}$ in old cavity to $6.21 \mathrm{~V} / \mathrm{pC} / \mathrm{m}$ in the new one. The values allowed in TESLA collider design project [7] are as follow: $\mathrm{k}_{\| \mathrm{HOM}} \leq 8 \mathrm{~V} / \mathrm{pC}$ and $\mathrm{k}_{\perp_{\mathrm{HOM}}} \leq 18$ $\mathrm{V} / \mathrm{pC} / \mathrm{m}$ for a bunch of $\sigma=1 \mathrm{~mm}$.

\subsection{Superconducting Superstructure}

The superstructure preserves the shape of TTF single cell but reduces to 7 the number of cells in one cavity. The input and output cell and interconnecting beam tubes are modified to allow the coupling of fundamental passband to the successive cavities. The string of 4 weakly coupled and separately tuned cavities form a basic unit (superstructure) with 28 supermodes. The number of RF power input couplers is thus reduced substantially ( by a factor more then 3 in the case of 4 cavity superstructure). 
The total length of $200 \mathrm{GeV}$ linac becomes shorter by $20 \%$. Those factors directly scale on investment cost reduction. The limited number of cells in cavity provide very important safety margin on field amplitude stability in individual cells.

Since the cavities in superstructure are no longer uncoupled the superstructure must be treated as one unit in wake fields evaluation. The calculations were made for single 7 cell cavity, two cavities and four cavities in superstructure. The wakes induced by $1 \mathrm{~mm}$ and $0.5 \mathrm{~mm}$ gaussian beam are illustrated in Fig. 4.

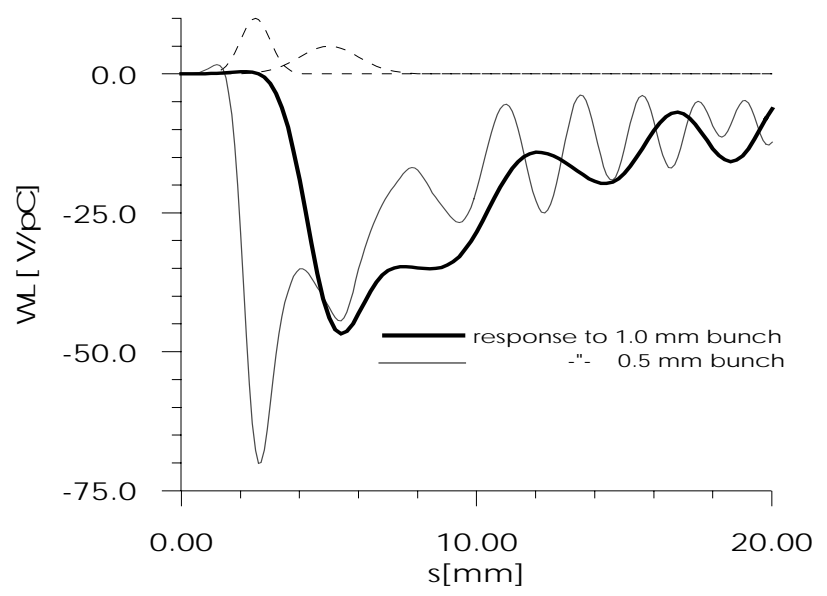

Fig.4 $\mathrm{W}_{\|}$wakes in 4 cavities superstructure due to $\sigma=1 \mathrm{~mm}$ and $0.5 \mathrm{~mm}$ gaussian bunch.

Table 3 lists the corresponding loss factors and Fig. 5 show the summed up longitudinal loss factor of 4 cavity superstructure.

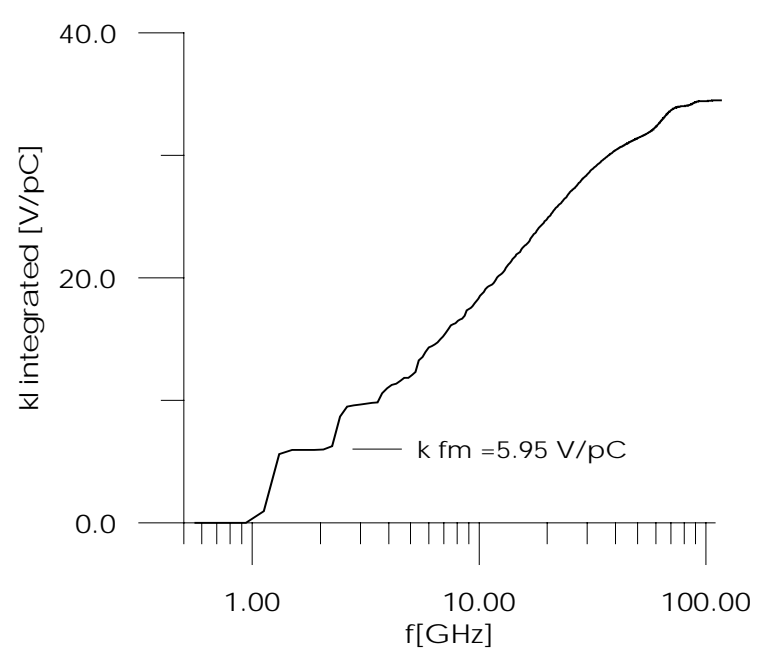

Fig. 5 Integrated $k_{\|}$of superstructure composed of 4 cavities. $\sigma=1 \mathrm{~mm}$ gaussian; $\mathrm{k}_{\| \text {total }}=34.56 \mathrm{~V} / \mathrm{pC}$.

To compare the TTF 9-cell cavity and superstructure the ratios of loss factor per 1 cell is taken. No obvious difference is found in energy loss factors. The difference in $\mathrm{k}_{\|} /$cell is within $2 \%$. The gain is in $\mathrm{k}_{\perp} /$ cell where this parameter is by $\sim 18 \%$ lower in superstructure.

Table 3. Longitudinal and transverse loss factors in superstructure

\begin{tabular}{|c|c|c|c|c|}
\hline$\sigma_{\text {bunch }}$ & $\begin{array}{c}\text { No of } \\
\text { cavities }\end{array}$ & $\begin{array}{c}\mathrm{k}_{\|} \\
{[\mathrm{V} / \mathrm{pC}]}\end{array}$ & $\begin{array}{c}\mathrm{k}_{\perp} \\
{[\mathrm{V} / \mathrm{pC} / \mathrm{m}]}\end{array}$ & $\begin{array}{c}\mathrm{k}_{\| \text {dipole }} \\
{[\mathrm{V} / \mathrm{pC} / \mathrm{m} 2]}\end{array}$ \\
\hline $1 \mathrm{~mm}$ & $1 \times 7$-cell & -10.65 & 15.29 & -10350 \\
\hline $1 \mathrm{~mm}$ & $2 \times 7$-cell & -18.64 & 27.4 & -19680 \\
\hline $1 \mathrm{~mm}$ & $4 \times 7$ cell & -34.73 & 52.54 & -39040 \\
\hline & & & & \\
\hline $0.5 \mathrm{~m}$ & 7 -cell & -18.29 & 11.7 & -16370 \\
\hline $0.5 \mathrm{~m}$ & $2 \times 7$-cell & -29.17 & 21.01 & -30600 \\
\hline $05 . \mathrm{mm}$ & $4 \times 7$ cell & -51.17 & 38.05 & -57960 \\
\hline
\end{tabular}

\section{SUMMARY AND CONCLUSIONS}

The wakepotentials excited in proposed new schemes of accelerating cavities were evaluated and compared. The most favourable is large iris 9-cell cavity where the losses due to bunch current are lowest. The superstructure is favorised by arguments of high R/Q, safe margins on electron emission and quench level and by substantial reduction of investment costs in Tesla collider realisation. The room temperature models of 7-cell cavities were built in our Institute and sent to DESY/Hamburg where the working parameters of superstructure will be checked experimentally.

\section{ACKNOWLEDGEMENTS}

The author wish to thank J. Sekutowicz for the discussions and supplying all necessary data on the new cavities, and Y.H. Chin for advises concerning the use of ABCI code. Author is also indebted to D. Proch and S. Kulinski for their constant interest and support in this work.

\section{REFERENCES}

[1] J. Sekutowicz, D. Proch, C. Tang, , Note on the SC Linear Collider TESLA Cavity Design”, Reports at the PAC 97, May12-16,1997,Vancouver,Canada.

[2] J.Sekutowicz, C.Tang, M.Ferrario, „Superconducting Superstructure for the TESLA Collider", DESY, TESLA 98-07

[3] E. Plawski, ,Wake-fields Induced by the Electron Beam Passing through the TESLA Accelerating System”, DESY, June1997, TESLA 97-12

[4] E.Haebel, A.Mosnier. „Large or Small Iris Aperture in SC Multicell Cavities" Proc. of The 5th Workshop on RF Superconductivity, Hamburg 1991

[5] E. Haebel, A. Mosnier, J. Sekutowicz, „Cavity Shape Optimisation for a Superconducting Linear Collider", Proc. of XV International Conf. on HEACC, Hamburg, 1992, p.957.

[6] Y.H. Chin, CERN-LEP/TH88-3 Report

[7] D.A. Edwards ed., "TESLA Test Facility LinacDesign Report”, DESY TESLA Rep. 95-1 